\title{
Pigmentation in Drosophila melanogaster reaches its maximum in Ethiopia and correlates most strongly with ultra-violet radiation in sub-Saharan Africa
}

Héloïse Bastide ${ }^{\dagger}$, Amir Yassin ${ }^{\dagger}$, Evan J Johanning and John E Pool ${ }^{*}$

\begin{abstract}
Background: Pigmentation has a long history of investigation in evolutionary biology. In Drosophila melanogaster, latitudinal and altitudinal clines have been found but their underlying causes remain unclear. Moreover, most studies were conducted on cosmopolitan populations which have a relatively low level of genetic structure and diversity compared to sub-Saharan African populations. We investigated: 1) the correlation between pigmentation traits within and between the thorax and the fourth abdominal segment, and 2) their associations with different geographical and ecological variables, using 710 lines belonging to 30 sub-Saharan and cosmopolitan populations.

Results: Pigmentation clines substantially differed between sub-Saharan and cosmopolitan populations. While positive correlations with latitude have previously been described in Europe, India and Australia, in agreement with Bogert's rule or the thermal melanism hypothesis, we found a significant negative correlation in Africa. This correlation persisted even after correction for altitude, which in its turn showed a positive correlation with pigmentation independently from latitude. More importantly, we found that thoracic pigmentation reaches its maximal values in this species in high-altitude populations of Ethiopia (1,600-3,100 m). Ethiopian flies have a diffuse wide thoracic trident making the mesonotum and the head almost black, a phenotype that is absent from all other sub-Saharan or cosmopolitan populations including high-altitude flies from Peru $(\sim 3,400 \mathrm{~m})$. Ecological analyses indicated that the variable most predictive of pigmentation in Africa, especially for the thorax, was ultra-violet (UV) intensity, consistent with the so-called Gloger's rule invoking a role of melanin in UV protection.
\end{abstract}

Conclusion: Our data suggest that different environmental factors may shape clinal variation in tropical and temperate regions, and may lead to the evolution of different degrees of melanism in different high altitude populations in the tropics.

Keywords: Melanism, Drosophila, Thoracic trident, Bogert's rule, Gloger's rule, Adaptation, UV resistance

\section{Background}

Melanism, i.e. the presence of dark forms within a species [1], has a long history in evolutionary biology. Two lines of research have been undertaken: dissecting genetic loci that contribute to the development of melanic forms, and exploring the external ecological and historical factors that maintain or drive the evolution of melanism. The first line of research has led to the identification of

\footnotetext{
*Correspondence: jpool@wisc.edu

†Equal contributors

Laboratory of Genetics, University of Wisconsin-Madison, Madison, WI, USA
}

sets of orthologous genes responsible for the synthesis of tyrosine-derived melanin in different animal lineages. Most notable is the recurrent evolution of melanism due to independent mutations in MC1R gene in vertebrate species $[2,3]$. The second line has usually aimed to associate melanic polymorphism with different environmental clines, such as the industrial melanism of the peppered moth [1,4], and Gloger's rule in endotherms and Bogert's rule in ectotherms stating that pigmentation should decrease and increase with latitude, respectively [5]. 
Most of our knowledge about the developmental basis of melanin synthesis in insects draws from studies on Drosophila. Regulatory mutations in the yellow, ebony, tan and bric-à-brac genes have driven the evolution of melanism within and between different species [6-10]. In Drosophila melanogaster, two pigmentation traits have traditionally been investigated in natural populations: the thorax (mesonotum) which when darkly pigmented forms a black trident [11], and the abdomen, measured either as stripe width [12] or background pigmentation [13] on different segments. Geographical clines of the thoracic trident were shown relative to the latitude in Europe [14], India [15] and Australia [16], and to altitude in India $[15,17]$. In sub-Saharan Africa, no latitudinal cline for thoracic pigmentation was found [14]. Clines were also found in $D$. melanogaster abdominal pigmentation relative to latitude/altitude in India [18-20] and altitude in subSaharan Africa [13]. Geographical clines of abdominal pigmentation also occur in other species relative to latitude (D. dunni subgroup, [21]; D. simulans, [22]), altitude (D. immigrans, [23]; D. kikkawai, [24]; D. yakuba, [25]), longitude/aridity (D. americana, [26]), and forest density (D. polymorpha, [27]).

Sub-Saharan Africa harbors the ancestral range of D. melanogaster, while its cosmopolitan populations are thought to derive from a single 'out-of-Africa' event [28-30]. Moreover, the topography of Africa is a mosaic of lowlands and highlands that does not follow a latitudinal gradient. Such a rich genetic and topographic diversity is ideal for the investigation of the environmental factors that may contribute to the development of pigmentation clines. Several hypotheses have been proposed to explain clinal variation of Drosophila pigmentation (reviewed in [31]). The most invoked one, known as the 'thermal budget hypothesis' $[14,18]$ or 'thermal melanism' [32], states that dark cuticle is adaptive in cold habitats for its higher absorbance of solar radiation. Other hypotheses aimed to relate differences in pigmentation to desiccation tolerance $[19,20,27,33]$ or ultra-violet (UV) resistance [25,34-36]. Although crypsis with substrate/soil color was invoked as one of the best explanations for industrial melanism [1] and clinal variation in rodents [37], it has rarely been suggested for drosophilids [27,38]. Other biotic factors are known to be affected by pigmentation in Drosophila, such as immunity against infection [39] and sexual selection [40], but clinal variations due to these factors have not yet been investigated to our knowledge. these factors seem less likely to drive clinal variations. Although the different hypotheses are not mutually exclusive, it remains difficult to understand which is the major force or forces driving global or local clinal variation in D. melanogaster.

In this paper, we aimed at simultaneously analyzing latitudinal and altitudinal clines of both abdominal and thoracic pigmentations in sub-Saharan $D$. melanogaster populations. We are not aware of any previous study that simultaneously investigated the two characters in the same set of populations, but a recent experiment indicated a substantial degree of correlated response to artificial selection [41]. We thus investigated the correlation between different traits of pigmentation within and between the thorax and the fourth abdominal segment (A4), and investigated their correlations with different ecological variables. The recent availability of large GIS databases of climatological and geological data and computational tools now enables a better dissection of these environmental causes [5]. Previous studies emphasized the roles of temperature and aridity in the development of pigmentation clines in D. melanogaster, but our results indicate that the neglected role of UV resistance may be more relevant, at least in tropical Africa.

\section{Methods}

\section{Fly populations}

Table 1 shows the list of the 30 geographical populations that we used in our study. These populations were classified into two major clans: sub-Saharan and cosmopolitan (26 and 4 populations, respectively). The sub-Saharan clan was further divided into four subclans according to their population genetic structure revealed from recent genomic data [30]: west, east, ethiopian and south African subclans (11, 5, 4 and 6 populations, respectively; Figure 1).

Populations were also divided into three sets of data according to the location and date of pigmentation scoring: $I$ (Cornell University, Ithaca 2005), $D$ (University of California, Davis 2009) and $M$ (University of Wisconsin, Madison 2013). The $I$ data set includes populations whose abdominal pigmentation scores have already been published by Pool and Aquadro [13]. Among the 19 subSaharan populations studied by these authors, we excluded three populations from Eritrea, Kenya and South Africa due to elevated genomic evidence of recent admixture from cosmopolitan strains [30]. The $I$ and $D$ data sets consisted of 228 and 170 isofemale lines, whereas $M$ consisted of 312 lines that were inbred for eight generations (Table 1).

\section{Scoring pigmentation}

For each line, five males and ten females were maintained at $20^{\circ} \mathrm{C}$ and $\sim 75 \%$ humidity on standard Drosophila medium (containing molasses, corn meal, yeast, agar, and antimicrobial agents). One, 3-5 day old female from the progeny per line was photographed using an Amscope SM-4TZZ-144A dissection microscope under $\mathrm{CO}_{2}$ anesthesia. For the $I$ and $D$ data sets flies were photographed on lateral view, but for $M$ both lateral and dorsal views were taken. Photos were then analyzed using the ImageJ software package [42]. 
Table 1 Populations sampled in this study

\begin{tabular}{|c|c|c|c|c|c|c|c|}
\hline Population & Symbol & Latitude & Longitude & Altitude & Date & Data set & $N$ \\
\hline \multicolumn{8}{|l|}{ Sub-Saharan Africa } \\
\hline \multicolumn{8}{|l|}{ West } \\
\hline Dondé, Guinea & GU & 10.70 & -12.25 & 801 & 06/2004 & । & 21 \\
\hline Cotonou, Benin & $\mathrm{BN}$ & 6.35 & 2.43 & 52 & $05 / 2004$ & । & 8 \\
\hline Maiduguri, Nigeria & NG & 11.85 & 13.16 & 295 & 09/2004 & । & 9 \\
\hline Kareygorou, Niger & NR & 13.55 & 2.03 & 195 & $12 / 2004$ & । & 20 \\
\hline Yokadouma, Cameroon & $\mathrm{CY}$ & 3.52 & 15.05 & 561 & 04/2004 & । & 8 \\
\hline Mbalang-Djalingo, Cameroon & $C D$ & 7.32 & 13.73 & 1213 & 03/2004 & I, D & 20,6 \\
\hline Maroua, Cameroon & CM & 10.60 & 14.32 & 385 & $03 / 2004$ & । & 22 \\
\hline Nkouondja, Cameroon & $\mathrm{CN}$ & 5.50 & 10.68 & 1121 & $04 / 2004$ & I, D & 24,6 \\
\hline Mbengwi, Cameroon & CW & 6.02 & 10.00 & 1274 & $04 / 2004$ & I, D & 6,4 \\
\hline Oku, Cameroon & $\mathrm{CO}$ & 6.25 & 10.43 & 2169 & $04 / 2004$ & $I, D, M$ & $9,5,10$ \\
\hline Franceville, Gabon & GA & -1.65 & 13.60 & 332 & $03 / 2002$ & । & 19 \\
\hline \multicolumn{8}{|l|}{ East } \\
\hline Namulonge, Uganda & UG & 0.53 & 32.60 & 1134 & $04 / 2005$ & I, D, M & $20,21,17$ \\
\hline Cyangugu, Rwanda & $\mathrm{RC}$ & -2.29 & 28.55 & 1602 & $12 / 2008$ & $\mathrm{D}$ & 14 \\
\hline Gikongoro, Rwanda & RG & -2.49 & 28.92 & 1927 & $12 / 2008$ & $D, M$ & 25,25 \\
\hline Marigat, Kenya & $\mathrm{KR}$ & 0.47 & 35.98 & 1062 & $01 / 2009$ & D & 25 \\
\hline Malindi, Kenya & KM & -1.43 & 40.03 & 78 & $01 / 2009$ & $\mathrm{D}$ & 21 \\
\hline \multicolumn{8}{|l|}{ Ethiopia } \\
\hline Gambella, Ethiopia & EA & 8.25 & 34.59 & 525 & $12 / 2011$ & M & 6 \\
\hline Ziway, Ethiopia & $\mathrm{EZ}$ & 7.93 & 38.72 & 1642 & $12 / 2008$ & D & 25 \\
\hline Dodola, Ethiopia & ED & 6.98 & 39.18 & 2492 & $12 / 2008$ & $\mathrm{D}$ & 7 \\
\hline Fiche, Ethiopia & $\mathrm{EF}$ & 9.81 & 38.63 & 3070 & $12 / 2011$ & M & 44 \\
\hline \multicolumn{8}{|l|}{ South } \\
\hline Mwanza, Malawi & MW & -15.62 & 34.52 & 618 & 07/2001 & I, D & 13,11 \\
\hline Siavonga, Zambia & $\mathrm{Zl}$ & -16.54 & 28.72 & 530 & 07/2010 & M & 51 \\
\hline Lake Kariba, Zimbabwe & ZK & -16.52 & 28.80 & 619 & 05/1994 & । & 16 \\
\hline Sengwa, Zimbabwe & ZS & -18.16 & 28.22 & 865 & 09/1990 & I & 13 \\
\hline Phalaborwa, South Africa & $\mathrm{SP}$ & -23.94 & 31.14 & 375 & 07/2010 & M & 6 \\
\hline Dullstroom, South Africa & SD & -25.42 & 30.10 & 2000 & $12 / 2011$ & M & 49 \\
\hline \multicolumn{8}{|l|}{ Cosmopolitan } \\
\hline \multicolumn{8}{|l|}{ Palearctic } \\
\hline Cairo, Egypt & EG & 30.10 & 31.32 & 25 & $01 / 2011$ & M & 9 \\
\hline Lyon, France & $\mathrm{FR}$ & 45.77 & 4.86 & 175 & 07/2010 & M & 71 \\
\hline \multicolumn{8}{|l|}{ Neotropical } \\
\hline Puerto Maldonado, Peru & PM & -12.60 & -69.19 & 200 & $04 / 2013$ & M & 14 \\
\hline Cusco, Peru & PC & -13.52 & -71.97 & 3400 & $04 / 2013$ & M & 10 \\
\hline
\end{tabular}

$N=$ number of lines.

We scored different pigmentation traits on two cuticular structures: the fourth abdominal segment and the (thoracic) mesonotum (Figure 2). For abdominal pigmentation two traits were measured: pigmentation intensity near the anterior margin (A4 background), measured in greyscale \% as in Pool and Aquadro [13], and width of the posterior black stripe (A4 stripe) as in David et al. [12]. For the latter trait, we divided the width in pixels of the black stripe by the whole width in pixels of A4, rather than visually estimating the ratio. Both traits were measured approximately half-way between the dorsal midline and the dorsal-ventral (tergite- 


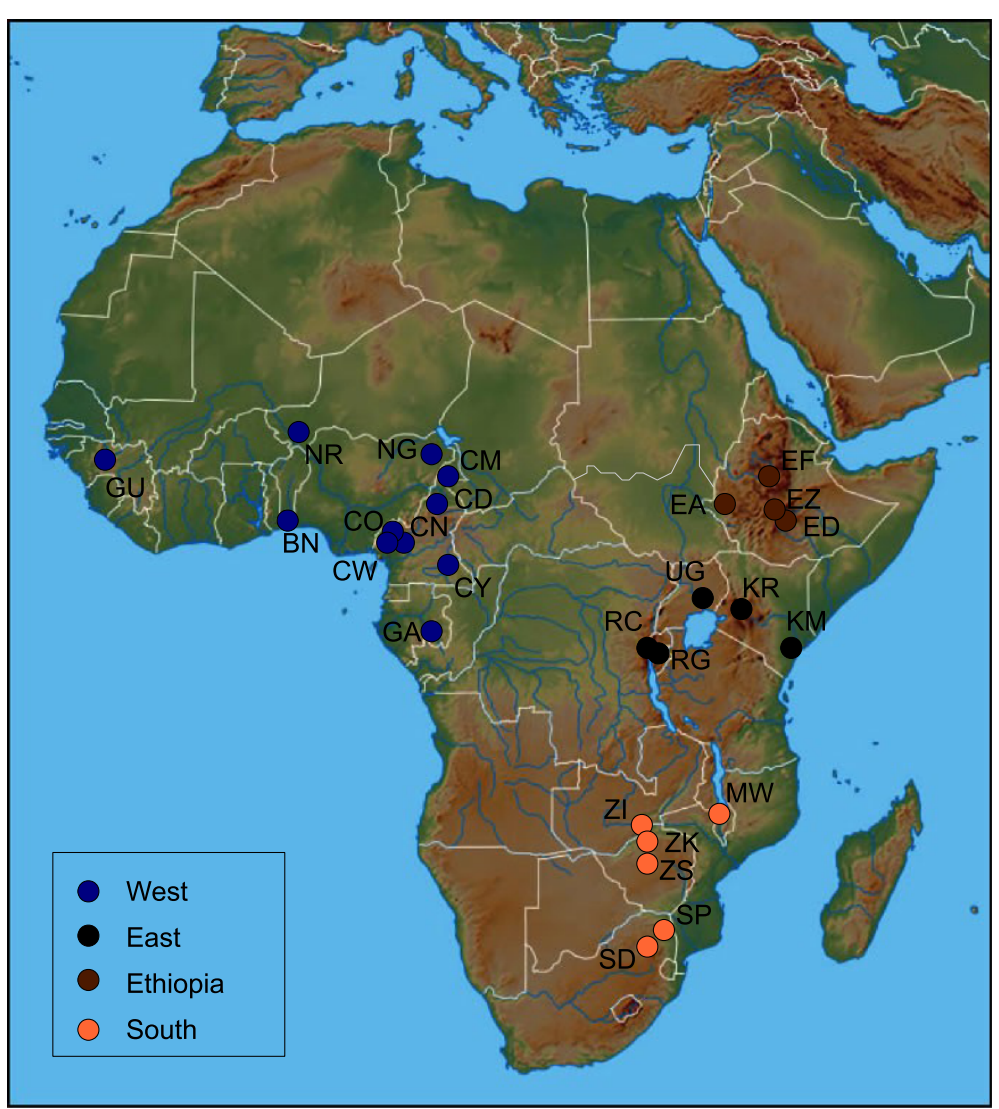

Figure 1 Drosophila melanogaster sub-Saharan populations used in this study. Colors refer to populations division into four subclans according to their genetic structure.

sternite) boundary. A4 stripe was measured for flies from the $M$ data set only. For the thorax, three pigmentation intensity traits were scored in greyscale \%: on the latero-anterior margin of the scutum near the humerus, on the posterior margin of the scutum near the scutoscutellar suture, and on the mesopleuron on the katepisternal sclerite above the level of the two large katerpisternal bristles (hereafter MPL). In addition, we scored the thoracic trident according to the four phenotypic classes proposed by David et al. [14]: $0=$ no trident, $1=$ faint trident, $2=$ clearly marked trident, and $4=$ dark trident. Because humeral, presutural and trident pigmentation traits need to be scored from a dorsal perspective they were only scored for flies from the $M$ data set, whereas MPL was scored for all data sets.

Exposure time, zoom width and illumination level using an Amscope adaptor for LED lamp at maximum lighting were kept constant within each data set but they differed due to different laboratory equipments between the three sets. Flies were microphotographed on a fixed region of the $\mathrm{CO}_{2}$ pad, to minimize background effects. Since some strains were measured in different sets (Table 1), their A4 background means were used to scale greyscale measurements of $D$ and $M$ relative to $I$ using a linear model. To scale $D$ relative to $I$, three populations were used $(\mathrm{MW}=$ 53.6 and 62.6, UG $=68.2$ and 74.0, and RG $=61.4$ and 72.1, with scores indicating population means for measurements made in $D$ and $I$, respectively). This led to a relationship of $x_{I}=21.23+0.79 x_{D}\left(R^{2}=0.89\right)$, with $x_{D}$ being the mean of measurements scored in Davis and $x_{I}$ the scaled measurement relative to Ithaca. To scale $M$ relative to $I$, three data points were also used, corresponding to $\mathrm{CO}$, UG and ZK/ZI, with the latter being two populations from Zimbabwe and Zambia, respectively, that are less than $10 \mathrm{~km}$ apart and share similar habitats. The pigmentation scores $(\mathrm{CO}=62.0$ and $72.1, \mathrm{UG}=59.4$ and 74.0, and $\mathrm{ZI} / \mathrm{ZK}=41.8$ and 61.8 , with measurements indicating means for $M$ and $I$, respectively) led to a relationship of $x_{I}=37.92+0.58 x_{M}\left(R^{2}=0.93\right)$, with $x_{M}$ being the mean of measurements scored in Madison and $x_{I}$ the scaled measurement relative to Ithaca. These rescalings are unlikely to perfectly account for the differences between data sets, which may add noise to some analyses. However, we do not expect any strong bias in terms of environmental correlations, and we find no significant effect of data set on rescaled A4 and MPL pigmentation scores for rescaled A4 and MPL pigmentation scores, respectively: Kruskal-Wallis chi-squared $=4.46(P=0.1073)$ and $4.19(P=0.1233)$. 

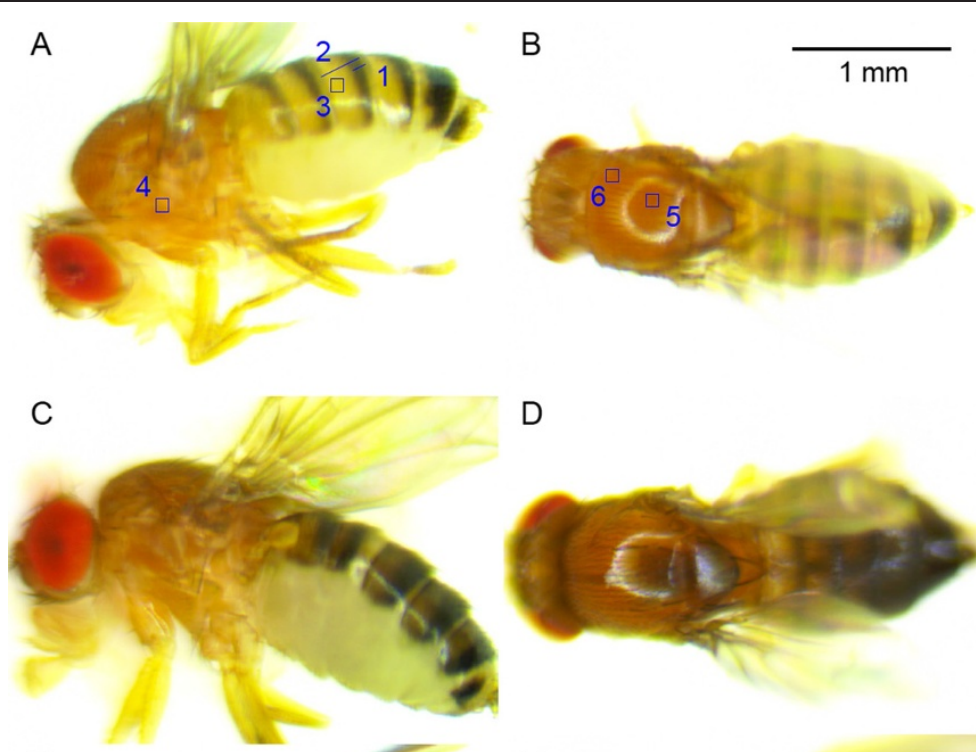

$\mathrm{D}$
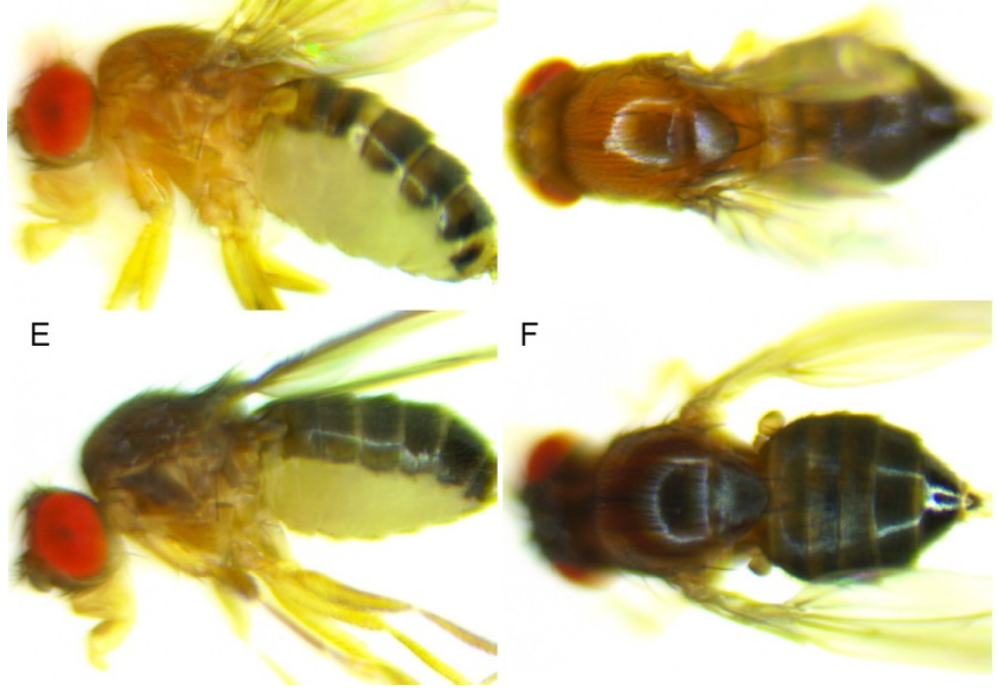

Figure 2 Natural variation of thoracic and abdominal pigmentation between three sub-Saharan populations of Drosophila melanogaster: (A-B) typically pigmented flies from Siavonga, Zambia, (C-D) moderately melanic flies from Nkouondja, Cameroon, and (E-F) intensely melanic flies from Dodola, Ethiopia. Pigmentation traits measured in this study on (A) lateral and (B) dorsal views: $1=$ A4 black stripe width, $2=$ A4 total tergite width, $3=$ A4 background, 4 = mesopleural $(\mathrm{MPL}), 5=$ presutural, $6=$ humeral.

\section{Statistical analyses}

Three main statistical analyses were conducted in this paper. First, we evaluated the levels of phenotypic correlations between the five pigmentation traits scored within two sub-Saharan populations representing phenotypic extremes of the $M$ data set. To correct for multiple correlation tests, we estimated the false discovery rate (FDR) for a given $P$ value, i.e. a $q$ value, and significance levels were considered at $q<0.05$, i.e. a $5 \%$ FDR cutoff.

Second, we simultaneously estimated latitudinal and altitudinal clines for the two measurements of abdominal and thoracic pigmentations (A4 background and MPL) scored on the three populations data sets, using a multiple linear regression model as in Munjal et al. [15]:

$$
y=a+b_{1} \text { lat. }+b_{2} \text { alt. }+\varepsilon
$$

where $y$ is the pigmentation score mean of a population, $a$ is the intercept, $b_{1}$ and $b_{2}$ are the slopes (or the clines) of the absolute latitude and altitude values, and $\varepsilon$ is the residual. Analyses were conducted for subSaharan populations only. For comparative purposes, we also independently estimated the zeroth-ordered correlation coefficient $\left(r_{0}\right)$ between each pigmentation trait, latitude and altitude, as well as the semi-partial correlation coefficient $\left(r_{\mathrm{s}}\right)$ of each pigmentation trait with the latitude or the altitude after controlling for the effect of the other geographical variable on pigmentation.

Third, we analyzed the correlation between A4 background and MPL and different ecological and historical factors that may affect pigmentation evolution. In order to determine the environmental factors that may explain each of the clines, we obtained GIS meteorological and geological data for each population. Meteorological data averaged over 22 years (from 1983 to 2005) were extracted as annual averages from the NASA Surface meteorology and Solar Energy: Global Data Sets website (www.eosweb.larc.nasa.gov). These included five radiation sets (namely, insolation incident, diffuse radiation, direct normal radiation and latitude tilt radiation, each measured in $\mathrm{kWh} / \mathrm{m}^{2} /$ day) and seven climatic sets (namely, average, minimum and maximum air temperatures and earth temperature measured in ${ }^{\circ} \mathrm{C}$, relative humidity in $\%$, atmospheric pressure in $\mathrm{kPa}$, and wind speed at $50 \mathrm{~m}$ 
Table 2 Correlation coefficients between different pigmentation traits within a lowland population (ZI, below the diagonal) and a highland population (EF, above the diagonal)

\begin{tabular}{lllllll}
\hline & A4 background & A4 stripe & Humeral & MPL & Presutural & Trident \\
\hline A4 background & & $0.332^{* *}$ & $0.525^{* * *}$ & $0.646^{* * *}$ & $0.673^{* * *}$ & $0.492^{* * *}$ \\
A4 stripe & $0.344^{*}$ & & 0.107 & $0.202^{*}$ & $0.260^{*}$ & $0.192^{*}$ \\
Humeral & -0.004 & -0.245 & & $0.678^{* * *}$ & $0.567^{* * *}$ & $0.374^{* *}$ \\
MPL & 0.232 & 0.198 & 0.210 & & $0.638^{* * *}$ \\
Presutural & 0.220 & -0.128 & $0.728^{* * *}$ & $0.546^{*}$ & $0.270^{*}$ \\
Trident & 0.106 & 0.024 & 0.282 & $0.458^{* *}$ & $0.823^{* * *}$ & $0.661^{* * *}$ \\
\hline
\end{tabular}

$\mathrm{A} 4=4^{\text {th }}$ abdominal segment, MPL $=$ mesopleuron. Significance levels ( $q$ values) are after FDR correction for multiple comparisons.

${ }^{*} q<0.05 ;{ }^{* *} q<0.01 ;{ }^{* * *} q<0.001$.

above ground in $\mathrm{m} / \mathrm{s}$ ). We also included annual average values of UV index from the Tropospheric Emission Monitoring Internet Service (www.temis.nl) in units of $25 \mathrm{~mW} / \mathrm{m}^{2}$. Geological data of soil sand, silt and clay contents at $<2 \mu \mathrm{m}$ in \% were obtained from the Africa Soil Information Service (www.ciesin.columbia.edu/afsis). We estimated the coefficients of correlation between pigmentation traits and each variable, and then chose for each ecological category that has previously been hypothesized to affect pigmentation (i.e. UV protection, thermal budget, desiccation and crypsis) a single variable showing the strongest correlation with pigmentation. In addition we included two principal component scores, namely PC1 and PC2, from Pool et al. [30] reflecting subclan differentiation to control for population structure and historical effects. To evaluate the relative importance of each of these ecological or historical factors, we used an informationtheoretic approach that ranks a number of linear modelbased hypotheses according to evidence ratios and posterior probabilities [43]. We conducted this analysis first using each factor as a separate model, and then using each factor and combination of two factors as models. For each model, the sample-size corrected Akaike information criterion $(\mathrm{AICc})$ was estimated, and models were ranked on the basis of increasing AICc and evaluated in respect to the descending probabilities $(w)$.

All statistical analyses were performed using the $\mathrm{R}$ software package (www.r-project.org). Semi-partial and second-ordered partial correlation analyses were conducted using the ppcor 1.0 package [44] in R. False Discovery Rate (FDR) control [45] was applied for multiple tests of phenotypic correlations between traits using the LBE 1.22 software package [46] in R. For model set evaluation, we modified the $\mathrm{R}$ code provided by Correa and Hendry [47] to fit our data.

\section{Results}

\section{Correlation between pigmentation traits}

The lowland, light ZI population from Zambia (occupying the suggested ancestral range of this species [30]) and the

Thoracic trident

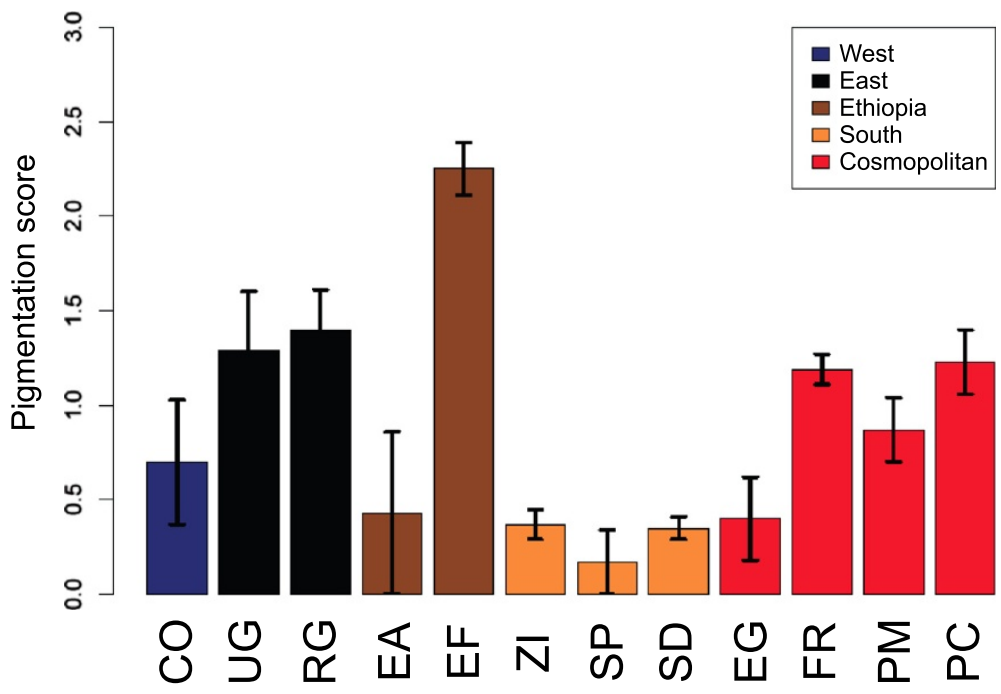

Figure 3 Average thoracic trident pigmentation scores in $\boldsymbol{D}$. melanogaster populations of the $\boldsymbol{M}$ data set. Error bars indicate standard errors of the means. 

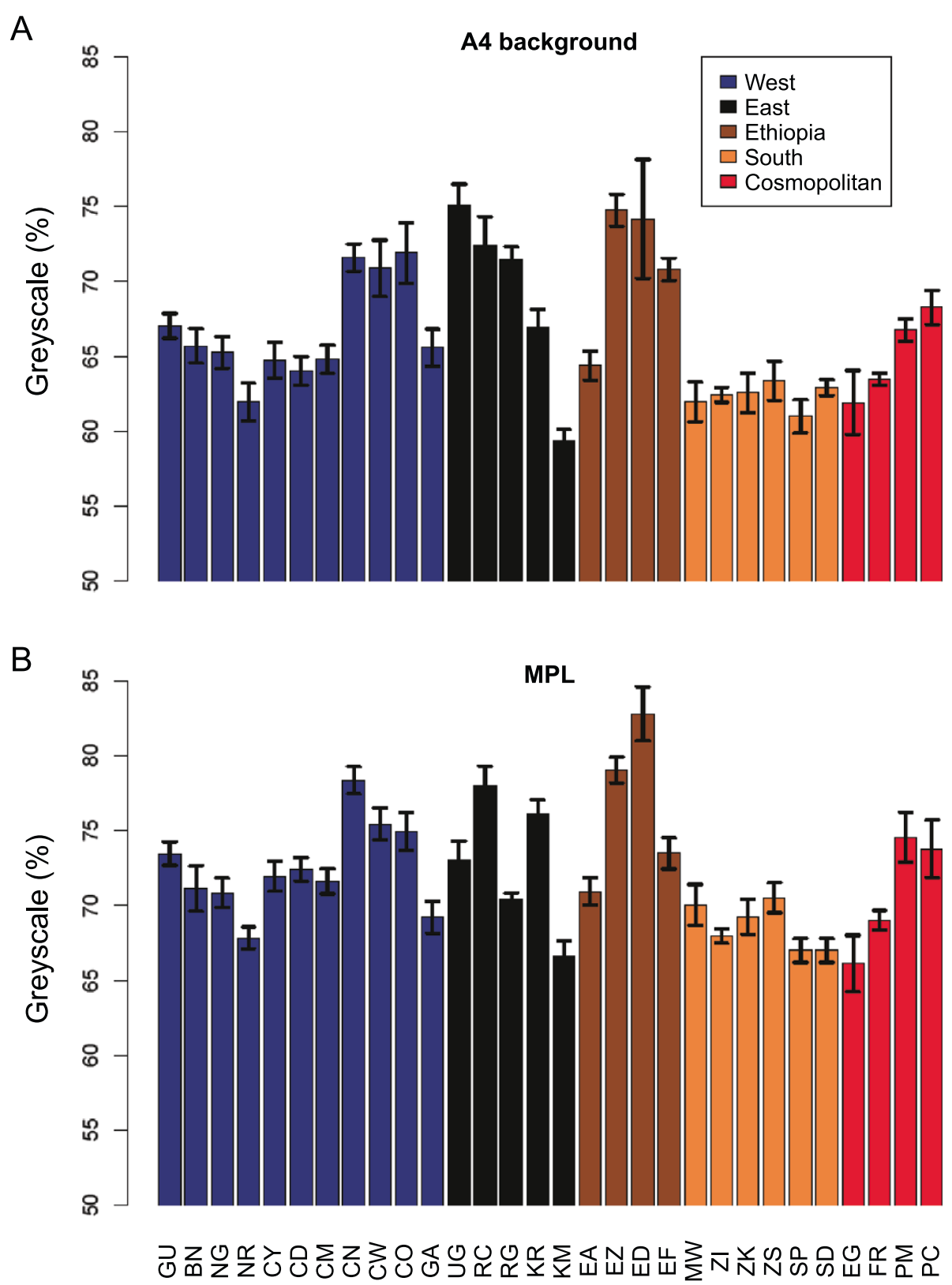

Figure 4 Population means of (A) A4 and (B) MPL pigmentation scores of all data sets.

highland, dark EF population from Ethiopia represented the two pigmentation extremes of the $M$ data set (Figure 2). In both populations, correlations between pigmentation traits within each of the two segments were positive and significant (Table 2). However, the two populations differed in the sign and significance of the correlations between the segments. In Zambia, no significant correlation was found between an abdominal pigmentation trait and a thoracic trait and some coefficients had negative values. In Ethiopia, all coefficients were significantly positive after FDR correction for multiple comparisons, possibly indicating a correlated genetic
Table 3 Tukey's ad hoc comparisons of A4 background (below diagonal) and MPL (above diagonal) between genetic subclans

\begin{tabular}{llllll}
\hline & West & East & Ethiopia & South & Cosmopolitan \\
\hline West & & 0.38 & 4.09 & 3.85 & 1.60 \\
East & 2.37 & & 3.71 & 4.23 & 1.97 \\
Ethiopia & 4.36 & 1.99 & & $7.94^{*}$ & 5.69 \\
South & 4.30 & 6.67 & $8.66^{*}$ & & 2.25 \\
Cosmopolitan & 1.57 & 3.94 & 5.93 & 2.73 & \\
\hline
\end{tabular}

${ }^{*} P<0.05 ;{ }^{* *} P<0.01 ;{ }^{* *} P<0.001$. 
Table 4 Multiple linear regressions of pigmentation traits on latitude and altitude in sub-Saharan Africa

\begin{tabular}{llll}
\hline Variable & Intercept & Latitude & Altitude \\
\hline A4 background & $65.866 \pm 1.209^{* * *}$ & $-0.321 \pm 0.081^{* * *}$ & $0.004 \pm 0.001^{* * *}$ \\
MPL & $71.859 \pm 1.336^{* * *}$ & $-0.257 \pm 0.089^{* *}$ & $0.003 \pm 0.001^{* *}$ \\
\hline${ }^{*}<<0.05 ;{ }^{* *} P<0.01 ;{ }^{* *} P<0.001$. & &
\end{tabular}

basis of abdominal and thoracic melanism in this population. The correlation between MPL, i.e. pigmentation on the pleura, and the trident, indicates that this trait should be moderately predictive of trident polymorphism in populations of the $I$ and $D$ data sets, for which no photomicrographs of the dorsal view were available. Interestingly, humeral pigmentation at the anterior portion of the thorax was only correlated with presutural pigmentation at the posterior portion of the scutum. Variation in thoracic background color is therefore not necessarily linked to either thoracic trident or abdominal pigmentation traits.

\section{A new phenotype of thoracic pigmentation in Ethiopia}

A uniquely melanic phenotypic class which goes beyond the scale defined by David et al. [14] was found and scored for some lines from the high-altitude Ethiopian population EF. These phenotypes have a diffuse wide trident on the thorax making the mesonotum (and the head) appearing completely black (Figure 2). They were scored as a fifth class (value $=4$ ), a phenotype that was absent in any previously examined sub-Saharan or cosmopolitan strain of $D$. melanogaster or its close relative $D$. simulans (J. R. David, pers. comm.). Consequently, the EF mean of thoracic trident was nearly twice that of other high latitude or altitude populations (e.g., France, Peru, Cameroon, Uganda and Rwanda) (Figure 3). The phenotype was also found in another high altitude Ethiopian population (ED), but it was absent from the low-altitude Ethiopian population EA.

\section{Geographical differentiation of pigmentation traits}

A4 background and MPL pigmentation variation between populations in all data sets after calibration with the scale of the $I$ data set showed similar geographical patterns between genetic clans (ANOVA's $F=3.09(P=0.0134)$ vs. $3.22(P=0.0292)$, respectively; Figure 4$)$. The two traits did not differ, however, in their variance, with the coefficient of variation being $6.74 \%$ for A4 background and $5.63 \%$ for MPL $(F$-test $=1.43 ; P=0.83,[48])$. Tukey's pairwise test showed a single significant pigmentation difference between Ethiopian and south African populations (Table 3; $P=0.0127$ and 0.0152 for A4 background and MPL, respectively). Remarkably, the uniquely melanic thoracic phenotype of high-altitude Ethiopian populations found at altitudes ranging between 1,600 and 3,100 $\mathrm{m}$ was not found in any other high-altitude sub-Saharan or even cosmopolitan population, including the population from Cusco, Peru (3,400 m). Melanism from Ethiopian highland strains thus appears to greatly exceed the pigmentation of any previously described $D$. melanogaster populations.

\section{Opposite latitudinal clines between sub-Saharan and cosmopolitan populations}

A4 background and MPL pigmentation in sub-Saharan Africa were significantly correlated with both latitude and altitude (Table 4; Figure 5). This situation is similar to what has previously been found on the Indian subcontinent $[15,19]$. Although in both cases pigmentations' slopes were positive for altitude, i.e. populations inhabiting high altitudes are darker, a negative slope was found for latitude in sub-Saharan Africa, whereas the latitudinal slope was
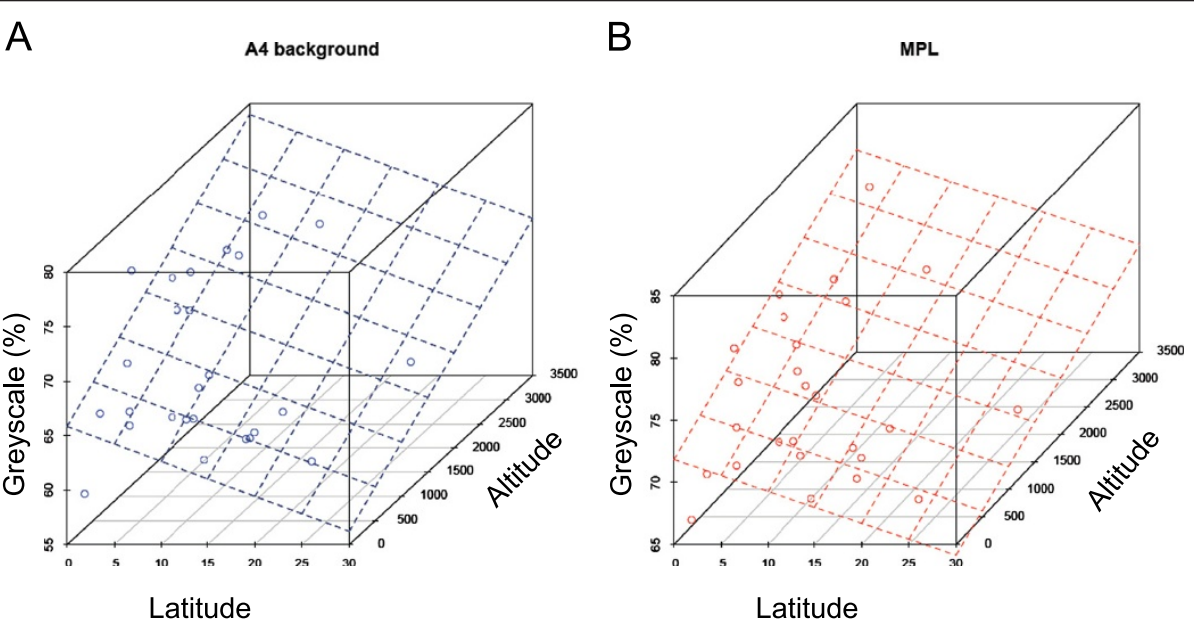

Figure 5 Negative latitudinal and positive altitudinal clines of population means of (A) A4 background and (B) MPL pigmentation scores in sub-Saharan Africa. The planes indicate the slopes from the multiple regression analyses. 
positive in India. This difference is most likely due to the topographic nature of the Indian subcontinent where both latitudes and altitudes covary, i.e. elevations increase northward toward the Himalayan plateau. In Africa, latitudes and altitudes do not covary $(r=-0.12$, $P=0.56)$ and the pigmentation clines with each factor persist after controlling for the other factor $\left(r_{\text {latitude }}=-0.64\right.$ $\left(P=6.7 \times 10^{-5}\right)$ and $-0.52(P=0.004), r_{\text {altitude }}=0.75$ $\left(P=7.2 \times 10^{-8}\right)$ and $0.59\left(P=4.8 \times 10^{-4}\right)$, for A4 background and MPL, respectively).

\section{Pigmentation correlates most strongly with UV radiation in sub-Saharan Africa}

Among the 18 environmental and historical factors considered in this study, pigmentation significantly correlated with 18 and 11 variables for A4 background and MPL, respectively (Table 5; Figure 6). For both traits UV index had the strongest correlations $(r=0.77$ and 0.78 for A4 and MPL, respectively; Figure 6A). In

\section{Table 5 Correlation of A4 background and MPL with different ecological and historical variables in sub-Saharan Africa}

\begin{tabular}{|c|c|c|}
\hline & A4 background & MPL \\
\hline \multicolumn{3}{|l|}{ Radiation } \\
\hline UV index & $0.737^{* * *}$ & $0.760^{* * *}$ \\
\hline Insolation incident & $-0.157^{*}$ & -0.005 \\
\hline Diffuse radiation & $0.411^{* *}$ & 0.300 \\
\hline Direct normal radiation & $-0.319^{*}$ & -0.186 \\
\hline Latitude tilt radiation & $-0.279^{*}$ & -0.136 \\
\hline Clear sky radiation & $0.324^{*}$ & $0.389^{*}$ \\
\hline \multicolumn{3}{|l|}{ Temperature } \\
\hline Average temperature & $-0.596^{* * *}$ & $-0.495^{* *}$ \\
\hline Average minimum temperature & $-0.485^{* *}$ & $-0.413^{*}$ \\
\hline Average maximum temperature & $-0.640^{* * *}$ & $-0.532^{* *}$ \\
\hline Earth temperature & $-0.665^{* * *}$ & $-0.501^{* *}$ \\
\hline \multicolumn{3}{|l|}{ Humidity } \\
\hline Relative humidity & $0.414^{* *}$ & 0.256 \\
\hline Atmospheric pressure & $-0.658^{* * *}$ & $-0.607^{* *}$ \\
\hline \multicolumn{3}{|l|}{ Wind } \\
\hline Wind speed & $-0.305^{*}$ & -0.227 \\
\hline \multicolumn{3}{|l|}{ Soil } \\
\hline Sand & $-0.612^{* * *}$ & $-0.520^{* *}$ \\
\hline Silt & $0.714^{* * *}$ & $0.652^{* *}$ \\
\hline Clay & $0.178^{*}$ & 0.113 \\
\hline \multicolumn{3}{|l|}{ Genetic structure } \\
\hline PC1 & $0.465^{* *}$ & $0.491^{* *}$ \\
\hline PC2 & $-0.323^{*}$ & $-0.376^{*}$ \\
\hline
\end{tabular}

order to evaluate the different ecological and historical hypotheses, we conducted a model rank analysis using five environmental and two population genetic structure factors. We found UV radiation to be the most explanatory factor for variation in sub-Saharan Africa, when each environmental factor is considered separately ( $\mathrm{g}_{01}$ in Tables 6 and 7 ). Flies are darker at higher levels of UV index $\left(\right.$ slope $=3.95 \pm 0.74\left(P=1.7 \times 10^{-5}\right)$ and $3.58 \pm 0.62\left(P=6.6 \times 10^{-6}\right)$, for A4 background and MPL, respectively). Soil silt content $\left(\mathrm{g}_{05}\right)$ was always the second most explanatory factor (slope $=0.35 \pm 0.07$ $\left(P=4.3 \times 10^{-5}\right)$ and $0.28 \pm 0.07 \quad\left(P=3.1 \times 10^{-4}\right)$, for A4 background and MPL, respectively), but for both traits it was less likely than UV index (evidence ratio: $E_{\mathrm{g} 01, \mathrm{~g} 05}=2.6$ and 49.0, for A4 background and MPL, respectively). Similar results were obtained when combinations of traits were analyzed in a multivariate regression context (Tables 8 and 9). For MPL, the first four models, which weighted for $\sim 75 \%$ of the variance among models, were models including UV index alone or in combinations (Table 8). For A4 background, the most explanatory model which weighted for $61 \%$, did not include UV index. Instead this model was explained by correlations with temperature and the first principal component of genetic differentiation (slopes $=-1.08 \pm 0.17\left(P=1.97 \times 10^{-6}\right)$ and $27.08 \pm 5.51\left(P=5.7 \times 10^{-5}\right)$, respectively $)$, although the second and third most likely combinations did include UV. Thus, the unique melanic phenotype in Ethiopia may have evolved to protect against UV radiation, which reaches its maximum levels $\left(>300 \mathrm{~mW} / \mathrm{m}^{2}\right)$ in the Ethiopian highlands. However, this hypothesis requires further study, as does the potential role of other ecological factors.

\section{Discussion}

\section{Pigmentation as a modular trait}

Insect pigmentation can be regarded as a modular trait: its development depends on a conserved network of structural genes of the melanin synthesis pathway whose expression levels may differ between different body organs [38]. We investigated this hypothesis within two segments: the $2^{\text {nd }}$ thoracic segment (mesonotum) and the $4^{\text {th }}$ abdominal segments (A4), which are developmentally four segments apart. Previous studies in Drosophila showed that the degree of genetic correlation of pigmentation decreases with increasing distance between body segments $[49,50]$. In agreement with these studies, we did not find a significant correlation between the two segments in the lowland ZI population which is presumably under no directional selection for pigmentation. On the other hand, pigmentation traits correlated between the two segments in the high-altitude Ethiopian population, potentially due to selectively favored alleles that alter multiple pigmentation traits. A recent experimental selection study 

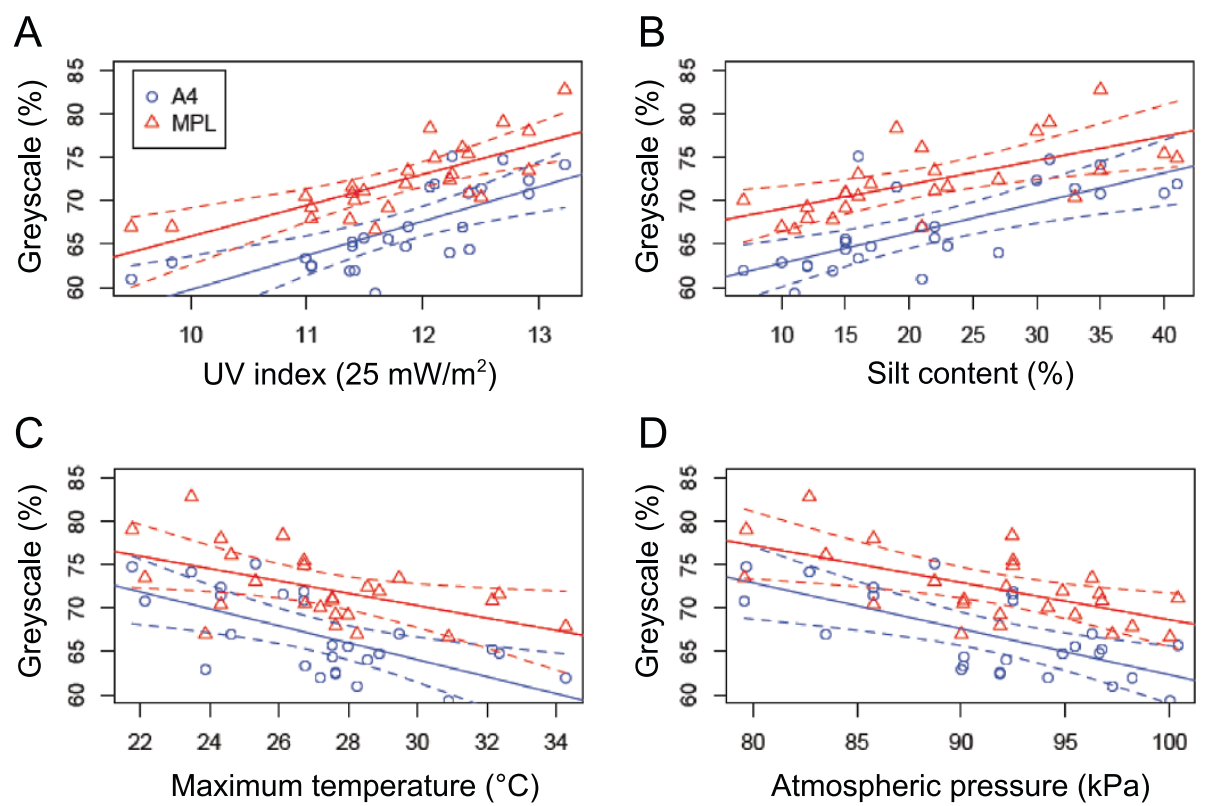

Figure 6 Linear regression of population means of A4 background (blue) and MPL (red) pigmentation scores on (A) ultra-violet (UV) index, (B) silt content, (C) average maximum temperature, and (D) atmospheric pressure, in sub-Saharan Africa.

has shown the presence of correlated response to selection between the thorax and the $2^{\text {nd }}$ abdominal segment [41]. Geographical variation of A4 pigmentation in sub-Saharan Africa and of thoracic trident in Australia were found to be related to differences in ebony expression levels $[7,13,16]$, but detailed molecular dissection of the regulation of ebony expression revealed that different enhancers of the gene affect different body parts $[7,10,51]$.

\section{Adaptive significance of Drosophila melanism}

Latitudinal or altitudinal clines of abdominal and thoracic pigmentation has previously been found in $D$. melanogaster [13-20] and also in other drosophilid species [21-25]. In all cases darker phenotypes were encountered at high latitudes or altitudes, but the exact cause of the clinal variation remained elusive. The most invoked hypothesis was the thermal budget or thermal melanism stating that darker flies absorbs better solar radiation in colder environments [32]. This might explain some longitudinal clines too [52]. However, the high surface to volume ratio of these small insects may preclude them from maintaining a higher body temperature than their surroundings [53]. There is little experimental evidence that dark flies are warmer [54], and no experiment to our knowledge has shown a higher fitness of dark morphs in colder environments. The second most cited hypothesis is desiccation resistance. In India, variation in desiccation resistance parallels latitudinal and altitudinal clines of pigmentation [55], and there is experimental evidence that dark morphs are more resistant to desiccation than light morphs due to cuticular thickness [19]. However, the altitudinal cline of pigmentation in sub-Saharan D. yakuba was not associated with desiccation resistance [25].

Table 6 Univariate model set evaluation for A4 background

\begin{tabular}{|c|c|c|c|c|c|c|c|}
\hline Model & Formula & $k$ & RSS & Adjusted $R^{2}$ & AICc & Model likelihood & $w$ \\
\hline$g_{01}$ & UV index & 3 & 250.36 & 0.52 & 139.76 & 1.00 & 0.68 \\
\hline$g_{05}$ & Silt content & 3 & 269.41 & 0.49 & 141.67 & 0.39 & 0.26 \\
\hline$g_{04}$ & Atmospheric pressure & 3 & 311.23 & 0.41 & 145.42 & 0.06 & 0.04 \\
\hline$g_{02}$ & Mean max. temperature & 3 & 323.71 & 0.39 & 146.44 & 0.04 & 0.02 \\
\hline go6 & Genetic PC1 & 3 & 430.20 & 0.18 & 153.84 & 0.00 & 0.00 \\
\hline$g_{03}$ & Relative humidity & 3 & 454.76 & 0.14 & 155.28 & 0.00 & 0.00 \\
\hline$g_{07}$ & Genetic PC2 & 3 & 491.51 & 0.07 & 157.30 & 0.00 & 0.00 \\
\hline go8 & naïve & 2 & 548.85 & 0.00 & 157.60 & 0.00 & 0.00 \\
\hline
\end{tabular}

$k=$ number of parameter estimates, RSS = residual sum of squares, AICc $=$ Akaike information criterion adjusted for the sample size, $w=$ conditional model probability (likelihood of model $i$ divided by the sum of model likelihoods). 
Table 7 Univariate model set evaluation for MPL

\begin{tabular}{llllllll}
\hline Model & Formula & $\boldsymbol{k}$ & RSS & Adjusted $\boldsymbol{R}^{\mathbf{2}}$ & AICc & Model likelihood & w \\
\hline g01 & UV index & 3 & 178.56 & 0.56 & 130.97 & 1.00 & 0.98 \\
g05 & Silt content & 3 & 243.52 & 0.40 & 139.04 & 0.02 & 0.02 \\
g04 & Atmospheric pressure & 3 & 267.16 & 0.34 & 141.45 & 0.01 & 0.01 \\
g02 & Average maximum temperature & 3 & 303.60 & 0.25 & 144.77 & 0.00 & 0.00 \\
g06 & Genetic PC1 & 3 & 321.44 & 0.21 & 146.26 & 0.00 & 0.00 \\
g07 & Genetic PC2 & 3 & 363.57 & 0.11 & 149.46 & 0.00 & 0.00 \\
g08 & naïve & 2 & 423.30 & 0.00 & 150.85 & 0.00 & 0.00 \\
g03 & Relative humidity & 3 & 395.63 & 0.03 & 151.66 & 0.00 & 0.00 \\
\hline
\end{tabular}

$k=$ number of parameter estimates, $\mathrm{RSS}=$ residual sum of squares, AICc $=$ Akaike information criterion adjusted for the sample size, $w=$ conditional model probability (likelihood of model $i$ divided by the sum of model likelihoods).

Table 8 Multivariate model set evaluation for A4

\begin{tabular}{|c|c|c|c|c|c|c|c|}
\hline Model & Formula & $k$ & RSS & Adjusted $R^{2}$ & AICC & Model likelihood & $w$ \\
\hline$g_{17}$ & Temp + PC1 & 4 & 157.74 & 0.69 & 130.56 & 1.00 & 0.61 \\
\hline$g_{08}$ & UV + Temp & 4 & 173.83 & 0.66 & 133.09 & 0.28 & 0.17 \\
\hline$g_{11}$ & UV + Silt & 4 & 189.09 & 0.63 & 135.28 & 0.09 & 0.06 \\
\hline$g_{16}$ & Temp + Silt & 4 & 195.87 & 0.61 & 136.19 & 0.06 & 0.04 \\
\hline$g_{23}$ & AtmP + Silt & 4 & 196.90 & 0.61 & 136.33 & 0.06 & 0.03 \\
\hline$g_{24}$ & AtmP + PC1 & 4 & 199.13 & 0.61 & 136.62 & 0.05 & 0.03 \\
\hline$g_{10}$ & $U V+A t m P$ & 4 & 206.78 & 0.59 & 137.60 & 0.03 & 0.02 \\
\hline$g_{19}$ & $\mathrm{RH}+\mathrm{AtmP}$ & 4 & 210.71 & 0.58 & 138.09 & 0.02 & 0.01 \\
\hline$g_{01}$ & UV & 3 & 250.36 & 0.52 & 139.76 & 0.01 & 0.01 \\
\hline go9 & $U V+R H$ & 4 & 228.52 & 0.55 & 140.20 & 0.01 & 0.00 \\
\hline$g_{20}$ & $\mathrm{RH}+$ Silt & 4 & 237.10 & 0.53 & 141.16 & 0.01 & 0.00 \\
\hline$g_{27}$ & All & 9 & 112.68 & 0.71 & 141.16 & 0.00 & 0.00 \\
\hline$g_{05}$ & Silt & 3 & 269.41 & 0.49 & 141.67 & 0.00 & 0.00 \\
\hline$g_{13}$ & $U V+P C 2$ & 4 & 249.97 & 0.50 & 142.53 & 0.00 & 0.00 \\
\hline$g_{12}$ & $U V+P C 1$ & 4 & 250.00 & 0.50 & 142.54 & 0.00 & 0.00 \\
\hline$g_{04}$ & AtmP & 3 & 311.23 & 0.41 & 145.42 & 0.00 & 0.00 \\
\hline$g_{02}$ & Temp & 3 & 323.71 & 0.39 & 146.44 & 0.00 & 0.00 \\
\hline$g_{25}$ & AtmP + PC2 & 4 & 297.46 & 0.41 & 147.06 & 0.00 & 0.00 \\
\hline$g_{15}$ & Temp + AtmP & 4 & 298.47 & 0.41 & 147.14 & 0.00 & 0.00 \\
\hline$g_{14}$ & Temp + RH & 4 & 305.03 & 0.40 & 147.71 & 0.00 & 0.00 \\
\hline$g_{18}$ & Temp + PC2 & 4 & 323.17 & 0.36 & 149.21 & 0.00 & 0.00 \\
\hline$g_{21}$ & $\mathrm{RH}+\mathrm{PC1}$ & 4 & 383.28 & 0.24 & 153.65 & 0.00 & 0.00 \\
\hline$g_{22}$ & $\mathrm{RH}+\mathrm{PC2}$ & 4 & 383.91 & 0.24 & 153.69 & 0.00 & 0.00 \\
\hline go6 & PC1 & 3 & 430.20 & 0.18 & 153.84 & 0.00 & 0.00 \\
\hline$g_{26}$ & $P C 1+P C 2$ & 4 & 390.20 & 0.23 & 154.11 & 0.00 & 0.00 \\
\hline$g_{03}$ & $\mathrm{RH}$ & 3 & 454.76 & 0.14 & 155.28 & 0.00 & 0.00 \\
\hline$g_{07}$ & PC2 & 3 & 491.51 & 0.07 & 157.30 & 0.00 & 0.00 \\
\hline$g_{28}$ & naïve & 2 & 548.85 & 0.00 & 157.60 & 0.00 & 0.00 \\
\hline
\end{tabular}

$\mathrm{UV}=\mathrm{UV}$ index, Temp = average maximum temperature, $\mathrm{RH}=$ relative humidity, AtmP = atmospheric pressure, $\mathrm{PC} 1$ and $\mathrm{PC} 2=$ genetic principal components, $k=$ number of parameter estimates, $\mathrm{RSS}=$ residual sum of squares, $\mathrm{AICc}=$ Akaike information criterion adjusted for the sample size, $w=$ conditional model probability (likelihood of model $i$ divided by the sum of model likelihoods). 
Table 9 Multivariate model set evaluation for MPL

\begin{tabular}{|c|c|c|c|c|c|c|c|}
\hline Model & Formula & $k$ & RSS & Adjusted $R^{2}$ & AICc & Model likelihood & w \\
\hline$g_{08}$ & UV + Temp & 4 & 153.29 & 0.61 & 129.82 & 1.00 & 0.25 \\
\hline$g_{11}$ & UV + Silt & 4 & 154.44 & 0.60 & 130.01 & 0.91 & 0.22 \\
\hline$g_{01}$ & UV & 3 & 178.56 & 0.56 & 130.97 & 0.56 & 0.14 \\
\hline$g_{10}$ & $U V+A t m P$ & 4 & 161.08 & 0.59 & 131.11 & 0.52 & 0.13 \\
\hline$g_{17}$ & Temp + PC1 & 4 & 169.94 & 0.56 & 132.50 & 0.26 & 0.06 \\
\hline$g_{24}$ & AtmP $+P C 1$ & 4 & 170.22 & 0.56 & 132.54 & 0.26 & 0.06 \\
\hline$g_{13}$ & $U V+P C 2$ & 4 & 176.26 & 0.55 & 133.45 & 0.16 & 0.04 \\
\hline$g_{09}$ & $U V+R H$ & 4 & 178.27 & 0.54 & 133.75 & 0.14 & 0.03 \\
\hline$g_{12}$ & $U V+P C 1$ & 4 & 178.50 & 0.54 & 133.78 & 0.14 & 0.03 \\
\hline$g_{23}$ & AtmP + Silt & 4 & 194.80 & 0.50 & 136.05 & 0.04 & 0.01 \\
\hline$g_{16}$ & Temp + Silt & 4 & 211.45 & 0.46 & 138.18 & 0.02 & 0.00 \\
\hline$g_{05}$ & Silt & 3 & 243.52 & 0.40 & 139.04 & 0.01 & 0.00 \\
\hline$g_{19}$ & $\mathrm{RH}+\mathrm{AtmP}$ & 4 & 236.64 & 0.39 & 141.11 & 0.00 & 0.00 \\
\hline$g_{20}$ & $\mathrm{RH}+$ Silt & 4 & 239.69 & 0.38 & 141.44 & 0.00 & 0.00 \\
\hline$g_{04}$ & AtmP & 3 & 267.16 & 0.34 & 141.45 & 0.00 & 0.00 \\
\hline$g_{27}$ & All & 9 & 116.06 & 0.62 & 141.93 & 0.00 & 0.00 \\
\hline$g_{25}$ & AtmP + PC2 & 4 & 266.41 & 0.32 & 144.19 & 0.00 & 0.00 \\
\hline$g_{15}$ & Temp + AtmP & 4 & 266.84 & 0.31 & 144.23 & 0.00 & 0.00 \\
\hline$g_{02}$ & Temp & 3 & 303.60 & 0.25 & 144.77 & 0.00 & 0.00 \\
\hline$g_{26}$ & $P C 1+P C 2$ & 4 & 278.17 & 0.29 & 145.31 & 0.00 & 0.00 \\
\hline$g_{06}$ & PC1 & 3 & 321.44 & 0.21 & 146.26 & 0.00 & 0.00 \\
\hline$g_{18}$ & Temp + PC2 & 4 & 299.19 & 0.23 & 147.21 & 0.00 & 0.00 \\
\hline$g_{14}$ & Temp + RH & 4 & 302.17 & 0.22 & 147.47 & 0.00 & 0.00 \\
\hline$g_{21}$ & $\mathrm{RH}+\mathrm{PC} 1$ & 4 & 315.41 & 0.19 & 148.58 & 0.00 & 0.00 \\
\hline$g_{07}$ & $\mathrm{PC2}$ & 3 & 363.57 & 0.11 & 149.46 & 0.00 & 0.00 \\
\hline$g_{22}$ & $\mathrm{RH}+\mathrm{PC2}$ & 4 & 328.39 & 0.16 & 149.63 & 0.00 & 0.00 \\
\hline$g_{28}$ & naïve & 2 & 423.30 & 0.00 & 150.85 & 0.00 & 0.00 \\
\hline$g_{03}$ & $\mathrm{RH}$ & 3 & 395.63 & 0.03 & 151.66 & 0.00 & 0.00 \\
\hline
\end{tabular}

$\mathrm{UV}=\mathrm{UV}$ index, $\mathrm{Temp}=$ average maximum temperature, $\mathrm{RH}=$ relative humidity, $\mathrm{AtmP}=$ atmospheric pressure, $\mathrm{PC} 1$ and $\mathrm{PC}=$ genetic principal components, $k=$ number of parameter estimates, RSS = residual sum of squares, AIC $=$ Akaike information criterion adjusted for the sample size, $w=$ conditional model probability (likelihood of model $i$ divided by the sum of model likelihoods).

We conducted intensive correlation studies between clinal variation in pigmentation and different environmental factors and found that UV radiation was the strongest predictor of pigmentation traits especially for thoracic pigmentation (MPL). For abdominal pigmentation (A4 background), UV was also the strongest explanatory factor when factors were analyzed separately, but combinations of other factors such as temperature and population history might also be relevant. We did not find any relevance to atmospheric pressure or relative humidity, the two factors which may be the most explanatory for a desiccation-resistance hypothesis. In endotherms, pigmentation tends to increase with decreasing latitudes, the so-called Gloger's rule [5] (cf. [56] for an example in humans). In Drosophila, the opposite was always encountered, i.e. a positive relationship between pigmentation and latitude, in Europe, India and Australia [14-16,18]. However, David et al. [14] noted that latitudinal clines for thoracic pigmentation were only found in the temperate region encompassing North Africa and Europe (above $30^{\circ}$ ), whereas pigmentation in India also correlated with altitude which covaries with latitude [15]. Pool and Aquadro [13] found a negative latitudinal cline in subSaharan Africa, but the cline was not significant when they corrected for altitudinal effect. In our study, the negative latitudinal cline persisted even after correcting for altitudes. This may be due to our inclusion of highaltitude populations from both higher and lower latitudes. Our study thus provides the first evidence of a negative latitudinal cline of abdominal and thoracic pigmentation in sub-Saharan Africa in agreement with Gloger's rule but for ectotherms. 
Considering altitudinal clines of pigmentation, it has long been suggested that the "ecological importance of melanism at high altitudes is closely bound up with the fact that dense pigments serve as effective protection against the injurious effects of the intense ultra-violet" (p. 53, [57]). Scott [58] was "struck by the unicolorous black hue of the body" of some snails and one chloropid fly in high altitudes in Ethiopia, and we report here a uniquely dark morph of $D$. melanogaster from Ethiopia as well. Pool and Aquadro [13] demonstrated the presence of altitudinal clines of abdominal pigmentation in sub-Saharan Africa. Curiously, there is no obvious altitude-pigmentation cline in $D$. simulans (JEP, personal observation), even though this species is thought to spend more time outdoors than its close relative [59], and exists at high altitudes in Africa (e.g., Dodola, Ethiopia, where pigmentation is essentially a diagnostic trait between $D$. simulans and D. melanogaster).

Laboratory exposure of $D$. melanogaster to elevated UV radiation has typically shown wild type flies to be more resistant than light or dark pigmentation mutant strains [34-36], but flies experimentally fed melanin were found to be more resistant to irradiation [60]. Recently, Matute and Harris [25] reported the association between an altitudinal cline of pigmentation in Drosophila yakuba and UV resistance on two islands near western Africa. Surprisingly, the authors found that lightly pigmented strains had the longest survival after exposure to high levels of UV radiation. In contrast, the correlations we observe are consistent with a protective effect of dark pigmentation against UV radiation. These species could conceivably differ in the relationship between pigmentation and UV protection. Another possibility is that resistance to elevated UV doses in the laboratory may differ in important ways from UV resistance under natural conditions (e.g. due to the release of heat by melanin exposed to high levels of UV in the lab). Future UV resistance experiments with light and dark populations of D. melanogaster should be conducted to explain clinal variation in sub-Saharan Africa.

Our analyses were conducted on flies raised under similar laboratory conditions, and hence investigate genetic differences between populations. However, the phenotypes that occur in nature may be modulated by phenotypic plasticity [61], such as the documented influence of developmental temperature on $D$. melanogaster pigmentation [22,49,62-68], which could also differ between populations. Hence, it will also be worthwhile to study the influence of temperature and other environmental factors on the pigmentation of D. melanogaster from Ethiopia and elsewhere.

\section{Conclusion}

Ethiopian populations of $D$. melanogaster display uniquely melanic phenotypes not observed in other worldwide populations. Dark abdominal and thoracic pigmentation in Ethiopian flies appears to have a partly shared genetic basis. Resistance to ultraviolet radiation provides a promising hypothesis for geographic patterns of pigmentation among African populations.

\section{Competing interests}

The authors declare that they have no competing interests.

\section{Authors' contributions}

$\mathrm{HB}$ carried out the phenotypic scoring and drafted the manuscript. AY performed the statistical analyses and drafted the manuscript. EJJ maintained the fly stocks and took digital photos. JEP conceived the study, and participated in its design and coordination and helped to draft the manuscript. All authors read and approved the final manuscript.

\section{Acknowledgements}

We would like to thank four anonymous reviewers for their constructive critiques of the manuscript. This work was funded by an NSF research grant (DEB-1049777) to JEP.

Received: 3 March 2014 Accepted: 30 July 2014

Published: 13 August 2014

\section{References}

1. Majerus MEN: Melanism: Evolution in Action. Oxford; New York: Oxford University Press; 1998.

2. Hoekstra HE: Genetics, development and evolution of adaptive pigmentation in vertebrates. Heredity 2006, 97:222-234.

3. Martin A, Orgogozo V: The loci of repeated evolution: a catalog of genetic hotspots of phenotypic variation. Evolution 2013, 67:1235-1250.

4. Van't Hof AE, Edmonds N, Dalíková M, Marec F, Saccheri IJ: Industrial melanism in British peppered moths has a singular and recent mutational origin. Science 2011, 332:958-960.

5. Gaston KJ, Chown SL, Calosi P, Bernardo J, Bilton DT, Clarke A, ClusellaTrullas S, Ghalambor CK, Konarzewski M, Peck LS, Porter WP, Pörtner HO, Rezende EL, Schulte PM, Spicer JI, Stillman JH, Terblanche JS, van Kleunen M: Macrophysiology: a conceptual reunification. Am Nat 2009, 174:595-612.

6. Jeong S, Rebeiz M, Andolfatto P, Werner T, True J, Carroll SB: The evolution of gene regulation underlies a morphological difference between two Drosophila sister species. Cell 2008, 132:783-793.

7. Rebeiz M, Pool JE, Kassner VA, Aquadro CF, Carroll SB: Stepwise modification of a modular enhancer underlies adaptation in a Drosophila population. Science 2009, 326:1663-1667.

8. Wittkopp PJ, Stewart EE, Arnold LL, Neidert AH, Haerum BK, Thompson EM, Akhras S, Smith-Winberry G, Shefner L: Intraspecific polymorphism to interspecific divergence: genetics of pigmentation in Drosophila. Science 2009, 326:540-544.

9. Arnoult L, Su KFY, Manoel D, Minervino C, Magriña J, Gompel N, Prud'homme $B$ : Emergence and diversification of fly pigmentation through evolution of a gene regulatory module. Science 2013, 339:1423-1426.

10. Bastide H, Betancourt A, Nolte V, Tobler R, Stöbe P, Futschik A, Schlötterer C: A genome-wide, fine-scale map of natural pigmentation variation in Drosophila melanogaster. PLoS Genet 2013, 9:e1003534.

11. Morgan $\mathrm{TH}$, Bridges $\mathrm{CB}$ : The inheritance of a fluctuating character. J Gen Physiol 1919, 1:639-643.

12. David JR, Capy P, Gauthier J-P: Abdominal pigmentation and growth temperature in Drosophila melanogaster: similarities and differences in the norms of reaction of successive segments. J Evol Biol 1990, 3:429-445.

13. Pool JE, Aquadro CF: The genetic basis of adaptive pigmentation variation in Drosophila melanogaster. Mol Ecol 2007, 16:2844-2851.

14. David J, Capy P, Payant V, Tsakas S: Thoracic trident pigmentation in Drosophila melanogaster: differentiation of geographical populations. Genet Sel Evol 1985, 17:211-224

15. Munjal AK, Karan D, Gibert P, Moreteau B, Parkash R, David JR: Thoracic trident pigmentation in Drosophila melanogaster: latitudinal and altitudinal clines in Indian populations. Genet Sel Evol 1997, 29:601. 
16. Telonis-Scott M, Hoffmann AA, Sgrò CM: The molecular genetics of clinal variation: a case study of ebony and thoracic trident pigmentation in Drosophila melanogaster from eastern Australia. Mol Ecol 2011, 20:2100-2110.

17. Parkash R, Munjal AK: Phenotypic variability of thoracic pigmentation in Indian populations of Drosophila melanogaster. J Zool Syst Evol Res 1999 37:133-140.

18. Das A: Abdominal pigmentation in Drosophila melanogaster females from natural Indian populations. J Zool Syst Evol Res 1995, 33:84-87.

19. Parkash R, Rajpurohit S, Ramniwas S: Changes in body melanisation and desiccation resistance in highland vs. lowland populations of $D$. melanogaster. J Insect Physiol 2008, 54:1050-1056.

20. Parkash R, Sharma V, Kalra B: Climatic adaptations of body melanisation in Drosophila melanogaster from Western Himalayas. Fly (Austin) 2008, 2:111-117.

21. Heed WB, Krishnamurthy NB: Genetic studies on the cardini group of Drosophila in the West Indies. Univ Tex Publ 1959, 5914:155-179.

22. Capy P, David JR, Robertson A: Thoracic trident pigmentation in natural populations of Drosophila simulans: a comparison with D. melanogaster. Heredity 1988, 61:263-268.

23. Parkash R, Ramniwas S, Rajpurohit S, Sharma V: Variations in body melanization impact desiccation resistance in Drosophila immigrans from Western Himalayas. J Zool 2008, 276:219-227.

24. Parkash R, Sharma V, Kalra B: Sexual dimorphism for water balance mechanisms in montane populations of Drosophila kikkawai. Biol Lett 2010, 6:570-574

25. Matute DR, Harris A: The influence of abdominal pigmentation on desiccation and ultraviolet resistance in two species of Drosophila. Evolution 2013, 67:2451-2460

26. Wittkopp PJ, Smith-Winberry G, Arnold LL, Thompson EM, Cooley AM, Yuan DC, Song Q, McAllister BF: Local adaptation for body color in Drosophila americana. Heredity 2011, 106:592-602.

27. Brisson JA, De Toni DC, Duncan I, Templeton AR: Abdominal pigmentation variation in Drosophila polymorpha: geographic variation in the trait, and underlying phylogeography. Evol Int J Org Evol 2005, 59:1046-1059.

28. David JR, Capy P: Genetic variation of Drosophila melanogaster natural populations. Trends Genet TIG 1988, 4:106-111.

29. Baudry E, Viginier B, Veuille M: Non-African populations of Drosophila melanogaster have a unique origin. Mol Biol Evol 2004, 21:1482-1491.

30. Pool JE, Corbett-Detig RB, Sugino RP, Stevens KA, Cardeno CM, Crepeau MW, Duchen P, Emerson JJ, Saelao P, Begun DJ, Langley CH: Population genomics of sub-Saharan Drosophila melanogaster: African diversity and non-African admixture. PLoS Genet 2012, 8:e1003080.

31. True JR: Insect melanism: the molecules matter. Trends Ecol Evol 2003, 18:640-647.

32. Clusella Trullas S, van Wyk JH, Spotila JR: Thermal melanism in ectotherms. J Therm Biol 2007, 32:235-245.

33. Kalmus $\mathrm{H}$ : The resistance to desiccation of Drosophila mutants affecting body colour. Proc R Soc Lond B Biol Sci 1941, 130:185-201.

34. Mackenzie K, Muller HJ: Mutation effects of ultra-violet light in Drosophila. Proc R Soc Lond Ser B - Biol Sci 1940, 129:491-517.

35. Jacobs ME: Beta-alanine and adaptation in Drosophila. J Insect Physiol 1974, 20:859-866.

36. Wang Z, Liu R, Wang A, Du L, Deng X: Phototoxic effect of UVR on wild type, ebony and yellow mutants of Drosophila melanogaster: life span, fertility, courtship and biochemical aspects. Sci China Ser C Life Sci Chin Acad Sci 2008, 51:885-893.

37. Mullen LM, Hoekstra HE: Natural selection along an environmental gradient: a classic cline in mouse pigmentation. Evol Int J Org Evol 2008, 62:1555-1570.

38. Wittkopp PJ, Carroll SB, Kopp A: Evolution in black and white: genetic control of pigment patterns in Drosophila. Trends Genet 2003, 19:495-504.

39. Dombeck I, Jaenike J: Ecological genetics of abdominal pigmentation in Drosophila falleni: a pleiotropic link to nematode parasitism. Evol Int J Org Evol 2004, 58:587-596.

40. Llopart A, Elwyn S, Coyne JA: Pigmentation and mate choice in Drosophila. Nature 2002, 419:360. discussion 360

41. Rajpurohit S, Gibbs AG: Selection for abdominal tergite pigmentation and correlated responses in the trident: a case study in Drosophila melanogaster. Biol J Linn Soc 2012, 106:287-294.

42. Abramoff MD, Magalhães PJ, Ram SJ: Image processing with ImageJ. Biophotonics Int 2004, 11:36-42.

43. Anderson D: Model Based Inference in the Life Sciences: A Primer on Evidence New York, USA: Springer Verlag; 2008
44. Kim S-H, Yi SV: Understanding relationship between sequence and functional evolution in yeast proteins. Genetica 2007, 131:151-156.

45. Benjamini $Y$, Hochberg $Y$ : Controlling the false discovery rate: a practical approach to multiple testing. J R Stat Soc Ser B 1995, 57:289-300.

46. Dalmasso C, Broët $P$, Moreau T: A simple procedure for estimating the false discovery rate. Bioinformatics 2005, 21:660-668.

47. Correa C, Hendry AP: Invasive salmonids and lake order interact in the decline of puye grande Galaxias platei in western Patagonia lakes. Ecol Appl 2011, 22:828-842.

48. Lewontin RC: On the measurement of relative variability. Syst Zool 1966, 15:141-142.

49. Gibert P, Moreteau B, David JR: Developmental constraints on an adaptive plasticity: reaction norms of pigmentation in adult segments of Drosophila melanogaster. Evol Dev 2000, 2:249-260.

50. Yassin A, Carareto CMA, Noll F, Bicudo HEMC, David JR: Realized evolvability: quantifying phenotypic evolution in a Drosophila clade. J Zool Syst Evol Res 2011, 49:32-43.

51. Takahashi A, Takahashi K, Ueda R, Takano-Shimizu T: Natural variation of ebony gene controlling thoracic pigmentation in Drosophila melanogaster. Genetics 2007, 177:1233-1237.

52. Clusella-Trullas S, Terblanche JS: Local adaptation for body color in Drosophila americana: commentary on Wittkopp et al. Heredity 2011, 106:904-905.

53. Willmer PG, Unwin DM: Field analyses of insect heat budgets: reflectance, size and heating rates. Oecologia 1981, 50:250-255.

54. Hirai Y, Kimura MT: Incipient reproductive isolation between two morphs of Drosophila elegans (Diptera: Drosophilidae). Biol J Linn Soc 2008, 61:501-513.

55. Karan D, Dahiya N, Munjal AK, Gibert P, Moreteau B, Parkash R, David JR: Desiccation and starvation tolerance of adult Drosophila: opposite latitudinal clines in natural populations of three different species. Evolution 1998, 52:825-831.

56. Jablonski NG, Chaplin G: Human skin pigmentation as an adaptation to UV radiation. Proc Natl Acad Sci U S A 2010, 107(Suppl 2):8962-8968.

57. Mani M: Ecology and Biogeography of High Altitude Insects. The Hague: Junk; 1968.

58. Scott H: Biogeographical research in High Simien (northern Ethiopia), 1952-53. Proc Linn Soc Lond 1958, 170:1-91.

59. McKenzie JA: The distribution of vineyard populations of Drosophila melanogaster and Drosophila simulans during vintage and non-vintage periods. Oecologia 1974, 15:1-16.

60. Mosse IB, Lyakh IP: Influence of melanin on mutation load in Drosophila populations after long-term irradiation. Radiat Res 1994, 139:357-359.

61. Beldade P, Mateus ARA, Keller RA: Evolution and molecular mechanisms of adaptive developmental plasticity. Mol Ecol 2011, 20:1347-1363.

62. Das A, Mohanty S, Parida B: Abdominal pigmentation and growth temperature in Indian Drosophila melanogaster: evidence for genotypeenvironment interaction. J Biosci 1994, 19:267-275.

63. Gibert P, Moreteau B, Moreteau J-C, David JR: Growth temperature and adult pigmentation in two Drosophila sibling species: an adaptive convergence of reaction norms in sympatric populations? Evolution 1996, 50:2346-2353.

64. Gibert P, Moreteau B, David JR, Scheiner SM: Describing the evolution of reaction norm shape: body pigmentation in Drosophila. Evolution 1998, 52:1501-1506.

65. Gibert P, Moreteau B, David JR: Phenotypic plasticity of body pigmentation in Drosophila melanogaster: genetic repeatability of quantitative parameters in two successive generations. Heredity 2004, 92:499-507.

66. Pétavy G, Moreteau B, Gibert P, David JR: Phenotypic plasticity of body pigmentation in Drosophila: influence of a developmental thermoperiodic regime in two sibling species. Physiol Entomol 2002, 27:124-135.

67. Gibert J-M, Peronnet F, Schlötterer C: Phenotypic plasticity in Drosophila pigmentation caused by temperature sensitivity of a chromatin regulator network. PLoS Genet 2007, 3:e30.

68. Gibert J-M, Karch F, Schlötterer C: Segregating variation in the Polycomb group gene cramped alters the effect of temperature on multiple traits. PLOS Genet 2011, 7:e1001280.

doi:10.1186/s12862-014-0179-y

Cite this article as: Bastide et al:: Pigmentation in Drosophila

melanogaster reaches its maximum in Ethiopia and correlates most strongly with ultra-violet radiation in sub-Saharan Africa. BMC Evolutionary Biology 2014 14:179. 